\title{
ADEQUAÇÃO DO TESTE DE CONDUTIVIDADE ELÉTRICA PARA DETERMINAR A QUALIDADE FISIOLÓGICA DE SEMENTES DE JACARANDÁ-DA-BAHIA (Dalbergia nigra (VELL.) Fr.All. ex Benth.) ${ }^{1}$
}

\author{
MARCO ANTONIO MARQUES ${ }^{2}$, RINALDO CESAR PAULA ${ }^{3}$ E TERESINHA JESUS DELÉO RODRIGUES ${ }^{4}$
}

\begin{abstract}
RESUMO - Para testar o efeito da temperatura e do tempo de embebição nos valores de condutividade elétrica e verificar sua aplicabilidade para determinar a qualidade fisiológica de sementes de Dalbergia nigra (jacarandá-da-bahia), foram utilizadas sementes colhidos em três anos (lote I - 1998; lote II - 1997 e lote III - 1994). Inicialmente determinou-se o teor de água e depois conduziu-se os testes de germinação em laboratório e viveiro, utilizando-se quatro repetições de 25 sementes. Para estudar a condutividade elétrica (CE) foram utilizadas quatro repetições de 50 sementes. Cada subamostra foi colocada em recipiente contendo $75 \mathrm{ml}$ de água deionizada, embebidas por $6,12,18,24,30$ e 36 horas, a 20,25 e $30^{\circ} \mathrm{C}$. Sementes do lote II apresentaram maiores valores na primeira contagem da germinação, diferindo significativamente dos demais lotes. O lote III apresentou qualidade inferior. Com o aumento do período e da temperatura de embebição ocorreu aumento nos valores de $\mathrm{CE}$ das sementes dos três lotes. O lote III mostrou qualidade fisiológica inferior a dos lotes I e II, que apresentaram valores mais elevados de CE. Não houve diferenciação entre os lotes I e II. Concluiu-se que o teste de CE foi eficiente para diferenciar os lotes de sementes de Dalbergia nigra, com alto grau de associação com o teste de germinação.
\end{abstract}

Termos para indexação: Dalbergia nigra, condutividade elétrica, qualidade fisiológica.

\author{
ELECTRICAL CONDUCTIVITY TEST FOR THE DETERMINATION \\ OF THE PHYSIOLOGICAL SEED QUALITY OF \\ Dalbergia nigra (Vell.) Fr.All. ex Benth.
}

\begin{abstract}
This work was carried out to determine the effect of temperature and imbibitiom period on the electrical conductivity (EC) and to verify the applicability of the test in the determination of the physiological quality of the three seed lots of Dalbergia nigra. The results of germination tests in laboratory and nursery were correlationed with the datas of EC. The germination tests were conduced with four replications of the 25 seeds. Four replications of 50 seeds were used to measure the EC. Each subsample (replication) was placed in dish containing $75 \mathrm{ml}$ of deionized water and soaked for $6,12,18,24,30$ and 36 hours at 20,25 and $30^{\circ} \mathrm{C}$. Lot 3 seeds had the worst quality. Seeds belonging to lot I presented generally intermediary quality, but for some characters they were not different $(\mathrm{P}>0,05)$ from lot II. The EC values of the three seed lots were higher as the temperature and the imbibition period increased. Lot III, apparently, had the lowest physiological seed quality since showed the highest values of EC. There was not differentiation between lots I and II. It can be concluded that the EC test was efficient to discriminate Dalbergia nigra seed lots and presented high level of association with the germination test.

Index terms: Dalbergia nigra, electrical conductivity, physiological quality.
\end{abstract}

\footnotetext{
Aceito para publicação em 31.12.2001; trabalho realizado com apoio do CNPq.

${ }^{2}$ Eng $^{\circ}$ Agro $^{\circ}$, MSc. em Produção e Tecnologia de Sementes; e-mail: prosbo@ig.com.br
}

${ }^{3}$ Eng $^{\circ}$ Florestal, Doutor em Ciências Florestais, Prof. do Depto. Produção Vegetal, FCAV/UNESP, 14884-900, Jaboticabal-SP; e-mail: rcpaula@fcav.unesp.br

${ }^{4}$ Biológa, PhD., Prof do do Depto. Biologia Aplicada a Agropecuária, FCAV/ UNESP; e-mail: tdelro@fcav.unesp.br 


\section{INTRODUÇÃO}

O jacarandá-da-bahia (Dalbergia nigra (Vell.) Fr.All. ex Benth.) pertence à família Fabaceae, ocorrendo em Minas Gerais, São Paulo e Mato Grosso do Sul, principalmente no cerrado. Espécie tardia a clímax, é recomendada para arborização de pastos ou para arborização de culturas, e sua madeira é muito usada na fabricação de móveis de luxo (Rizzini, 1987).

A análise do vigor de sementes florestais, em sua grande maioria, restringe-se a avaliação de parâmetros derivados do teste de germinação, como primeira contagem da germinação, índice de velocidade e porcentagem de germinação, porcentagem de plântulas normais, crescimento e desenvolvimento de plântulas ou de partes da mesma. Geralmente, faz-se uso destes parâmetros para comparar diferentes tratamentos aplicados às sementes de um mesmo lote. Contudo, é de grande interesse, quando se dispõe de diferentes lotes de sementes, conhecer a qualidade fisiológica intrínseca a cada um. A queda na germinação é um dos últimos eventos que caracterizam o declínio na qualidade fisiológica de sementes e o teste de germinação, isoladamente, não é adequado para discriminar coretamente os lotes de sementes, pois, quando possuem porcentagem de germinação semelhantes, podem apresentar qualidades fisiológicas distintas (Bonner et al., 1994). A degeneração das membranas celulares com consequente perda da permeabilidade das membranas é o primeiro evento a ocorrer durante a deterioração das sementes (Delouche \& Baskin, 1973). Assim, testes que se baseiam na integridade do sistemas de membranas, conseguiriam detectar o processo de deterioração das sementes em sua fase inicial (Vieira, 1994). O teste de condutividade elétrica, que mede a quantidade de lixiviados na solução de embebição das sementes, foi proposto como teste de vigor das sementes, por estar, assim, diretamente relacionado à integridade do sistema de membranas (Marcos-Filho et al., 1987).

Poucos são os relatos do uso do teste de condutividade elétrica para avaliação do vigor de sementes florestais. Ferraz et al. (1991) fizeram uso do teste de condutividade elétrica para avaliar a viabilidade de sementes de Carapa procera DC., concluindo que o mesmo não foi apropriado como teste de vigor ou de viabilidade para sementes desta espécie. O teste de condutividade elétrica foi eficiente em detectar a queda da qualidade fisiológica de sementes de Cedrela fissilis Vell. (Borges et al., 1990), mas não para sementes de Piptadenia communis Benth. (Borges et al., 1992), ambas submetidas ao envelhecimento acelerado. Barbedo \& Cícero
(1998), concluíram que o teste de condutividade elétrica foi eficiente na separação de sementes de Inga uruguensis Hook. et Arn., para lotes com alta, média e baixa qualidade fisiológica.

Neste sentido, o trabalho teve como objetivo verificar o efeito da temperatura e do período de embebição nos valores de condutividade elétrica e verificar a aplica-bilidade deste teste na determinação da qualidade fisiológica de três lotes de sementes de Dalbergia nigra (jacarandá-da-bahia).

\section{MATERIAL E MÉTODOS}

Foram utilizadas sementes de Dalbergia nigra (Vell.) Fr. All. ex Benth. (jacarandá-da-bahia) pertencentes a três lotes (anos de colheita: lote I-1998, lote II-1997 e lote III-1994). Os lotes apresentavam idades e períodos de armazenamento diferentes e foram obtidos junto ao Laboratório de Análises de Sementes Florestais da Universidade Federal de Viçosa, Viçosa-MG.

Após colhidas, as sementes foram retiradas manualmente dos frutos, descartando-se as chochas e danificadas, sendo então armazenadas em tamboretes de fibra de madeira, em câmara fria $\left(5^{\circ} \mathrm{C}\right.$ e $85 \pm 5 \%$ de umidade relativa) até fevereiro de 2000, quando foram transferidas para a Faculdade de Ciências Agrárias e Veterinárias (FCAV/UNESP), Campus de Jaboticabal, Departamento de Biologia Aplicada à Agropecuária e armazenadas dentro de tamboretes de fibra de madeira, em câmara fria $\left(5-10^{\circ} \mathrm{C}\right.$ e $70-75 \%$ de UR), durante toda a fase experimental. Foram retiradas amostras de sementes de cada um dos lotes para as seguintes determinações: teor de água - foi determinado pelo método da estufa a $105 \pm 3^{\circ} \mathrm{C}$ por 24 horas (Brasil, 1992), utilizando-se três repetições de 100 sementes; porcentagem e índice de velocidade de germinação - o teste foi realizado em caixas plásticas de germinação $(11 \times 11 \mathrm{~cm})$, desinfetadas com hipoclorito de sódio a $5 \%$. Como substrato foram usadas duas folhas de papel para germinação. Todo o material, exceto as sementes e as caixas, foi autoclavado a $120^{\circ} \mathrm{C}$ por 20 minutos. O substrato foi umedecido com solução de nistatina a $0,2 \%$. Foram utilizadas quatro repetições de 25 sementes e o experimento foi conduzido em germinador vertical tipo $\mathrm{BOD}$, a $25^{\circ} \mathrm{C}$ constantes e fotoperíodo de oito horas. As contagens do número de sementes germinadas foram realizadas diariamente, sempre no mesmo horário, considerando-se como critério de germinação a protrusão da radícula $(2 \mathrm{~mm})$. Ao final do teste (11 dias) computou-se, também, a porcentagem de plântulas normais, ou seja, aquelas que apresentavam todas as estruturas essen- 
ciais perfeitas (Oliveira, 1993). Os dados obtidos foram expressos em porcentagem final de germinação $(G)$, porcentagem de plântulas normais (PNL) e índice de velocidade de germinação, determinado segundo Maguire (1962); primeira contagem da germinação - foi avaliada juntamente com o desenvolvimento do teste de germinação, sendo avaliada no sétimo dia após a instalação do teste; emergência, índice de velocidade de emergência e porcentagem de plântulas normais em viveiro - para esse estudo foi utilizado como substrato uma mistura à base de composto orgânico, casca de arroz carbonizada e terra de subsolo (na proporção de 6:3:1, $\mathrm{v} / \mathrm{v}$ ) e as sementes foram colocadas para germinar em casa de vegetação, com $50 \%$ de sombreamento e irrigação intermitente. A semeadura foi realizada em tubetes de plástico rígido com $50 \mathrm{~cm}^{3}$ de substrato, à profundidade aproximada de $1,0 \mathrm{~cm}$. A avaliação da emergência das plântulas foi realizada até sua estabilização, o que ocorreu com 23 dias. Avaliou-se a porcentagem final de emergência (E), a porcentagem de plântulas normais (PNV) e o índice de velocidade de emergência de plântulas (IVE), de acordo com Maguire (1962). Considerou-se como plântulas normais aquelas com todas as estruturas essenciais perfeitas (Oliveira, 1993). Durante o período experimental em viveiro, a temperatura média ambiental foi de $22,4^{\circ} \mathrm{C}$, a umidade relativa do ar de $73,5 \%$, a temperatura máxima de $29,4^{\circ} \mathrm{C}$ e a mínima de $17,1^{\circ} \mathrm{C}$; condutividade elétrica - foi realizado com quatro repetições de 50 sementes, pelo método de massa. Cada subamostra (repetição) foi pesada com precisão de duas casas decimais e a seguir, colocada em recipiente contendo $75 \mathrm{ml}$ de água deionizada (condutividade elétrica de $3 \mu \mathrm{mhos} / \mathrm{cm}$ ) e deixadas para embeber por $6,12,18,24,30$ e 36 horas, em germinadores com temperaturas de 20,25 e $30^{\circ} \mathrm{C}$. Após cada período reali- zou-se, imediatamente, a leitura da condutividade elétrica na solução de embebição, agitando-se levemente a mesma, utilizando-se de um condutivímetro Analyser 600. O resultado da leitura foi dividido pelo peso $(\mathrm{g})$ da respectiva subamostra, resultando em um valor expresso em $\mu \mathrm{mhos} / \mathrm{cm} / \mathrm{g}$ de semente.

No teste de condutividade elétrica, o delineamento experimental foi o inteiramente casualizado, em parcelas subdivididas para período de embebição. As parcelas foram representadas por um esquema fatorial $3 \times 3$ (três lotes e três temperaturas) e as subparcelas por seis períodos de embebição das sementes. Após a análise de variância, os graus de liberdade para a interação lote-temperatura-período de embebição foram decompostos pelo uso da análise de regressão polinomial até terceiro grau e as médias de lotes, temperaturas e de lotes para cada combinação temperatura-período de embebição foram comparadas pelo teste Tukey a $1 \%$ de probabilidade. Os resultados dos testes de condutividade elétrica foram correlacionados com os resultados dos demais testes pelo uso da análise de correlação simples, a 5\% pelo teste F. Os resultados dos testes de germinação, em laboratório e em viveiro, foram submetidos a análise de variância, seguindo um delineamento inteiramente casualizado, com três tratamentos (lotes) e quatro repetições de 25 sementes cada uma e as médias foram comparadas pelo teste Tukey a $1 \%$ de probabilidade.

\section{RESULTADOS E DISCUSSÃO}

Houve diferenças altamente significativas entre os lotes, para todas as características avaliadas, tanto em laboratório como viveiro (Tabela 1). Em laboratório, pelos critérios de primeira contagem da germinação (PC) e de índice de velocidade de germinação (IVG), o lote II foi superior aos lotes I e

TABELA 1. Resultados dos testes realizados em laboratório e em viveiro, com sementes de jacarandá-dabahia.

\begin{tabular}{|c|c|c|c|c|c|c|c|}
\hline \multirow{2}{*}{ Lotes } & \multicolumn{4}{|c|}{ Laboratório } & \multicolumn{3}{|c|}{ Viveiro } \\
\hline & $\mathrm{PC}(\%)$ & $\mathrm{G}(\%)$ & PNL (\%) & IVG & E $(\%)$ & PN (\%) & IVE \\
\hline Lote I & $60,5 \mathrm{~b}$ & $81,5 \mathrm{a}$ & $69,5 \mathrm{a}$ & $6,8 \mathrm{~b}$ & $61,0 \mathrm{a}$ & $38,0 \mathrm{a}$ & $1,20 \mathrm{a}$ \\
\hline Lote II & $79,5 \mathrm{a}$ & $90,5 \mathrm{a}$ & $74,0 \mathrm{a}$ & $8,6 \mathrm{a}$ & $71,0 \mathrm{a}$ & $43,0 \mathrm{a}$ & $1,60 \mathrm{a}$ \\
\hline Lote III & $10,5 \quad \mathrm{c}$ & $16,5 \mathrm{~b}$ & $6,5 \mathrm{~b}$ & $1,2 \quad \mathrm{c}$ & $3,0 \quad \mathrm{~b}$ & $1,0 \quad \mathrm{~b}$ & $0,04 \mathrm{~b}$ \\
\hline Valor de "F" & $57,09 * *$ & $292,00 * *$ & $149,92 * *$ & $346,09 * *$ & $88,55^{* *}$ & $52,63 * *$ & $26,91 * *$ \\
\hline CV (\%) & 18,81 & 7,52 & 12,33 & 7,44 & 17,34 & 23,14 & 32,86 \\
\hline Média & 50,17 & 62,83 & 50,00 & 5,57 & 45,00 & 27,33 & 0,94 \\
\hline
\end{tabular}

** - Valor significativo a $1 \%$ pelo teste $\mathrm{F}$.

Médias seguidas pela mesma letra, na coluna, não diferem entre si pelo teste Tukey a 5\%.

$\mathbf{C V}=$ Coeficiente de variação experimental; $\mathbf{P C}=$ Primeira contagem da germinação; $\mathbf{G}=$ Germinação; $\mathbf{P N L}=$ Porcentagem de plântulas normais em laboratório; IVG = Índice de velocidade de germinação; $\mathbf{E}=$ Emergência; $\mathbf{P N V}=$ Porcentagem de plântulas normais em viveiro; IVE = Índice de velocidade de emergência. 
III, e o lote I foi superior ao lote III. Para porcentagem final de germinação $(G)$ e porcentagem de plântulas normais (PNL), o lote III foi inferior aos lotes I e II.

No viveiro, os testes de emergência (E), porcentagem de plântulas normais (PNV) e índice de velocidade de emergência (IVE), classificaram os lotes I e II como sendo superiores ao lote III (Tabela 1). O teor de água das sementes foi de $9,36 \%$ para o lote I, $10,61 \%$ para o lote II e $9,56 \%$ para o lote III. De acordo com Vieira (1994), a uniformidade do teor de água é imprescindível para a obtenção de resultados confiáveis e consistentes nos testes de condutividade elétrica. Dessa forma, foi verificado para soja que o teor de água das sementes deverá estar entre 11 e $17 \%$, segundo a AOSA (1983) e entre 13 e 18\%, de acordo com Tao (1978) e Loeffler et al. (1988).

Observou-se efeitos altamente significativos para lotes, temperatura e períodos de embebição, bem como para as interações lotes $\mathrm{x}$ temperatura e lotes x período (Tabela 2). Os valores médios de condutividade elétrica (CE), evidenciam a superioridade do lote II, seguido pelo lote I e, o lote III como de qualidade inferior (Tabela 2), isso também se deve ao fato desse lote ser de 1994, enquanto os outros (I e II) de 1998 e 1997.

Houve diferença significativa entre os valores de $\mathrm{CE}$, obtidos nas três temperaturas de embebição, sendo observado maiores valores de CE nas temperatura mais elevadas (Tabela 2). Este aumento nos valores de CE com o aumento da temperatura de embebição das sementes, está relacionado com alterações na viscosidade da água, sendo que em geral, maiores temperaturas de embebição aumentam a quantidade e a velocidade de liberação de eletrólitos lixiviados (Murphy \& Noland, 1982); que de acordo com Loeffler et al. (1988) há um aumento na fluidez da membrana plasmática o que facilita a movimentação de água pela mesma. No entanto, de acordo com Leopold (1980), a elevação da temperatura aumenta a quantidade de lixiviados predominantemente em tecidos mortos e quantidades elevadas de lixiviados na solução de embebição pode ser

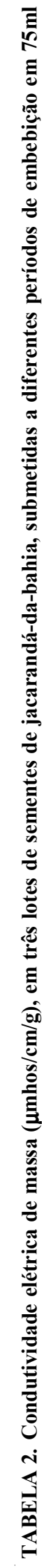

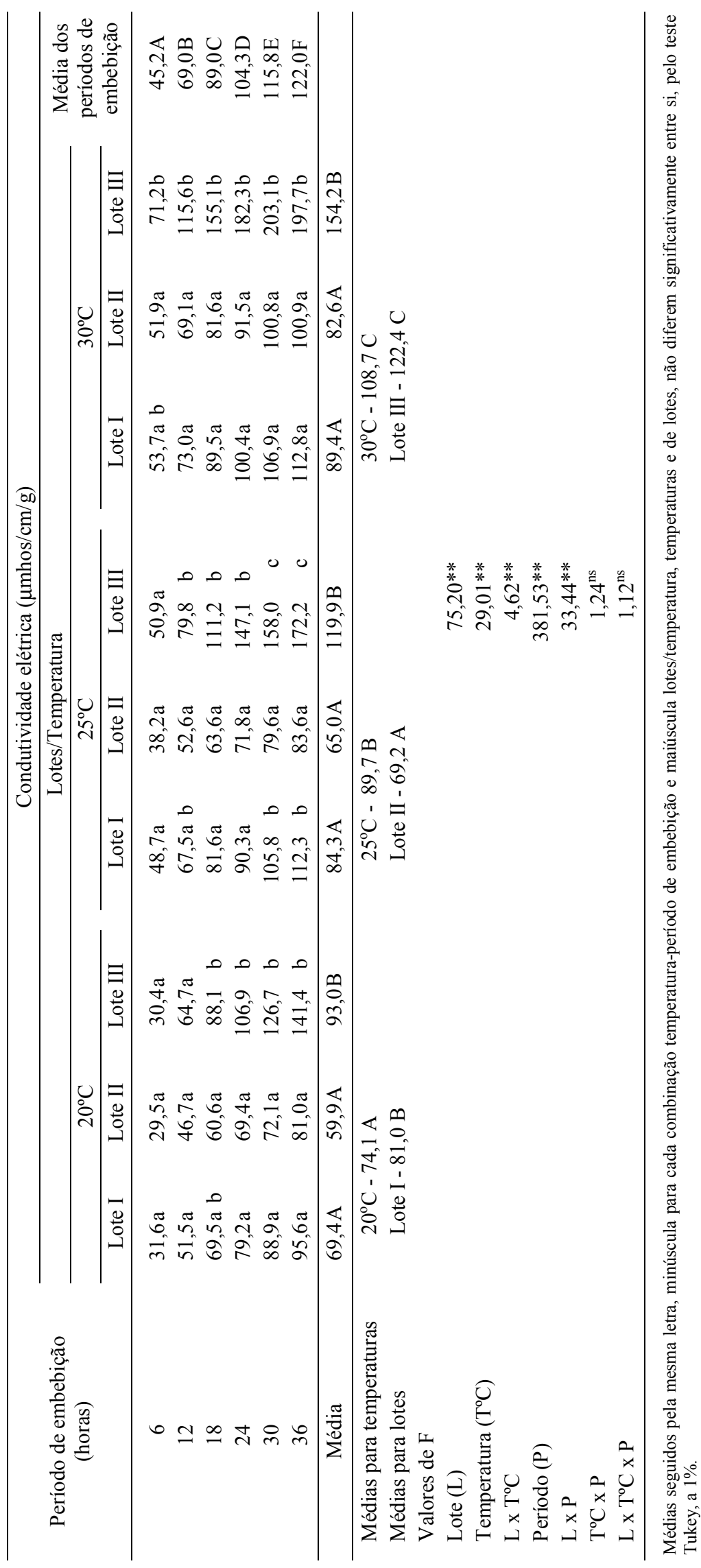


um indicativo da ineficiência e desorganização do sistema de membranas.

A determinação da temperatura ideal de embebição das sementes é de grande importância para o teste de condutividade elétrica, pois possibilita a diferenciação mais precisa dos lotes de sementes avaliados, no menor espaço de período possível. Rodo et al. (1998) trabalhando com sementes de tomate, concluíram que o teste de condutividade elétrica se mostrou mais eficiente na separação de lotes dessas sementes, quando o mesmo foi realizado a $25^{\circ} \mathrm{C}$.

Foi verificado, também, aumentos na CE com o aumento do período de embebição das sementes. Nota-se, contudo, que o acréscimo nos valores da CE, decresceram com o período de embebição, indicando uma tendência de estabilização nestes valores próximo a 36 horas de embebição (Tabela 2). A influência do período de embebição sobre os resultados da $\mathrm{CE}$ tem sido relatada por vários autores. Em geral, para sementes de maior tamanho o período de embebição, necessário para distinguir lotes com qualidades diferentes, tende a ser maior.

Para Loeffler et al. (1988), trabalhando com sementes de soja, quanto menos acentuadas forem as diferenças de vi- gor entre os lotes, períodos de embebição mais longos serão necessários para a diferenciação dos mesmos. Resultados concordantes aos obtidos por Loeffler et al. (1988), foram observados por Dias \& Marcos-Filho (1996), também, para sementes de soja, em que períodos mais curtos de embebição das sementes podem ser utilizados para a identificação de diferenças mais acentuadas entre lotes e períodos mais longos (maior que 16 horas) mostraram-se mais adequados para diferenciar lotes menos contrastantes.

Para espécies de sementes pequenas, o período de embebição pode variar de minutos a poucas horas, como observado para várias espécies olerícolas como aipo, alface e cenoura (Simon \& Mathavan, 1986 citados por Ribeiro, 1999.

O efeito do período de embebição, para cada uma das temperaturas, encontra-se na Tabela 3 e Figuras 1A, B e C. Para o lote I, de qualidade intermediária, os resultados encontrados para 25 e $30^{\circ} \mathrm{C}$, foram semelhantes, como pode ser observado pela variação dos valores de CE com o período de embebição. Para o lote II, de qualidade superior, as temperaturas de 20 e de $25^{\circ} \mathrm{C}$ proporcionaram resultados semelhantes. Apenas para o lote III, de qualidade inferior, é que o efei-

TABELA 3. Coeficientes de correlação simples entre os valores de condutividade elétrica e as características avaliadas em laboratório e em viveiro, para sementes de jacarandá-da-bahia.

\begin{tabular}{|c|c|c|c|c|c|c|c|c|}
\hline \multirow{2}{*}{$\begin{array}{l}\text { Temperatura } \\
\left({ }^{\circ} \mathrm{C}\right)\end{array}$} & \multirow{2}{*}{$\begin{array}{l}\text { Período de embebição } \\
\text { (horas) }\end{array}$} & \multicolumn{7}{|c|}{ Coeficientes de correlação } \\
\hline & & $\mathrm{PC}$ & $\mathrm{G}$ & PNL & IVG & $\mathrm{E}$ & $\mathrm{PNV}$ & IVE \\
\hline \multirow{6}{*}{20} & 6 & $0,10^{\mathrm{NS}}$ & $0,01^{\mathrm{NS}}$ & $0,03^{\mathrm{NS}}$ & $0,04^{\mathrm{NS}}$ & $0,10^{\mathrm{NS}}$ & $0,15^{\mathrm{NS}}$ & $0,17^{\mathrm{NS}}$ \\
\hline & 12 & $0,78^{* *}$ & $0,77^{* *}$ & $0,75^{* *}$ & $0,80^{* *}$ & $0,76^{* *}$ & $0,68^{*}$ & $0,66^{*}$ \\
\hline & 18 & $0,91^{* *}$ & $0,90^{* *}$ & $0,85^{* *}$ & $0,93^{* *}$ & $0,84^{* *}$ & $0,79^{* *}$ & $0,78^{* *}$ \\
\hline & 24 & $0,92^{* *}$ & $0,94^{* *}$ & $0,90^{* *}$ & $0,96^{* *}$ & $0,90^{* *}$ & $0,88^{* *}$ & $0,86^{* *}$ \\
\hline & 30 & $0,93^{* *}$ & $0,93^{* *}$ & $0,91^{* *}$ & $0,96^{* *}$ & $0,91^{* *}$ & $0,86^{* *}$ & $0,85^{* *}$ \\
\hline & 36 & $0,91^{* *}$ & $0,93^{* *}$ & $0,90^{* *}$ & $0,95^{* *}$ & $0,89^{* *}$ & $0,85^{* *}$ & $0,83^{* *}$ \\
\hline \multirow{6}{*}{25} & 6 & $0,50^{*}$ & $0,44^{\mathrm{NS}}$ & $0,48^{\mathrm{NS}}$ & $0,50^{*}$ & $0,45^{\mathrm{NS}}$ & $0,39^{\mathrm{NS}}$ & $0,41^{\mathrm{NS}}$ \\
\hline & 12 & $0,70^{*}$ & $0,67^{*}$ & $0,69^{*}$ & $0,71^{*}$ & $0,67^{*}$ & $0,61^{*}$ & $0,62^{*}$ \\
\hline & 18 & $0,82^{* *}$ & $0,82^{* *}$ & $0,84^{* *}$ & $0,85^{* *}$ & $0,83^{* *}$ & $0,76^{* *}$ & $0,78^{* *}$ \\
\hline & 24 & $0,90^{* *}$ & $0,95^{* *}$ & $0,94^{* *}$ & $0,95^{* *}$ & $0,92^{* *}$ & $0,88^{* *}$ & $0,87^{* *}$ \\
\hline & 30 & $0,84^{* *}$ & $0,87^{* *}$ & $0,88^{* *}$ & $0,88^{* *}$ & $0,86^{* *}$ & $0,81^{* *}$ & $0,81^{* *}$ \\
\hline & 36 & $0,86^{* *}$ & $0,88^{* *}$ & $0,90^{* *}$ & $0,90^{* *}$ & $0,88^{* *}$ & $0,83^{* *}$ & $0,82^{* *}$ \\
\hline \multirow{6}{*}{30} & 6 & $0,67^{*}$ & $0,70^{*}$ & $0,77^{* *}$ & $0,70^{*}$ & $0,80^{* *}$ & $0,70^{*}$ & $0,70^{*}$ \\
\hline & 12 & $0,85^{* *}$ & $0,91^{* *}$ & $0,95^{* *}$ & $0,90^{* *}$ & $0,93^{* *}$ & $0,87^{* *}$ & $0,86^{* *}$ \\
\hline & 18 & $0,87^{* *}$ & $0,93^{* *}$ & $0,97^{* *}$ & $0,92^{* *}$ & $0,95^{* *}$ & $0,90^{* *}$ & $0,89^{* *}$ \\
\hline & 24 & $0,89^{* *}$ & $0,94^{* *}$ & $0,97^{* *}$ & $0,93^{* *}$ & $0,95^{* *}$ & $0,90^{* *}$ & $0,89^{* *}$ \\
\hline & 30 & $0,87^{* *}$ & $0,92^{* *}$ & $0,96^{* *}$ & $0,91^{* *}$ & $0,95^{* *}$ & $0,89^{* *}$ & $0,88^{* *}$ \\
\hline & 36 & $0,75^{* *}$ & $0,80^{* *}$ & $0,83^{* *}$ & $0,79^{* *}$ & $0,88^{* *}$ & $0,81^{* *}$ & $0,80^{* *}$ \\
\hline
\end{tabular}

$* *=$ Valor significativo a $1 \%$ pelo teste $\mathrm{F} ; *$ = Valor significativo a $5 \%$ pelo teste $\mathrm{F}$; NS - Valor não significativo a $5 \%$, pelo teste $\mathrm{F}$.

$\mathbf{P C}=$ Primeira contagem da germinação; $\mathbf{G}=$ Germinação; $\mathbf{P N L}=$ Porcentagem de plântulas normais em laboratório; $\mathbf{I V G}=$ Índice de velocidade de germinação; $\mathbf{E}=$ Emergência; $\mathbf{P N V}=$ Porcentagem de plântulas normais em viveiro; $\mathbf{I V E}=$ Índice de velocidade de emergência 

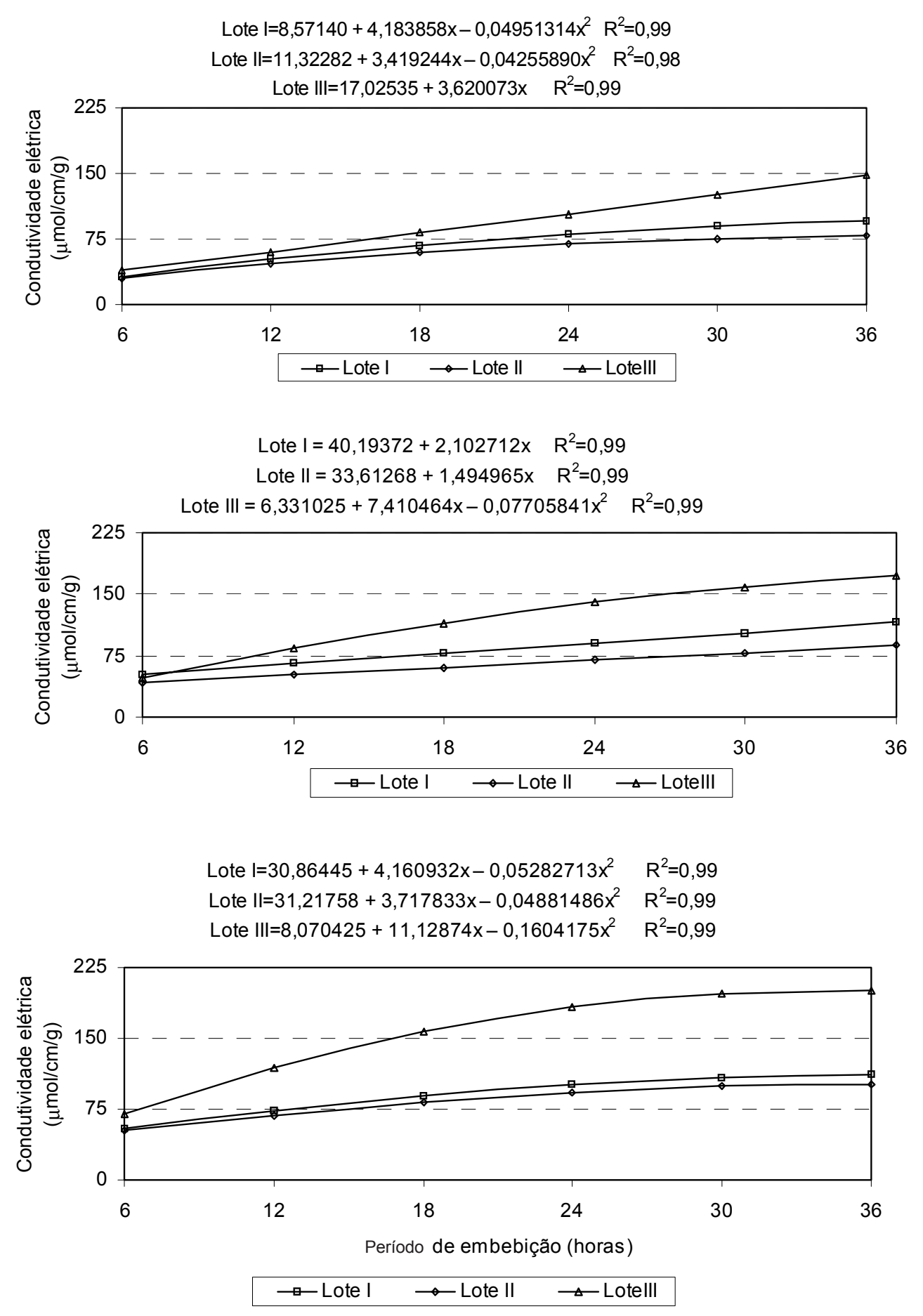

FIG 1. Condutividade elétrica $(\mu \mathrm{mhos} / \mathrm{cm} / \mathrm{g})$ de três lotes de sementes de jacarandá-dabahia, incubadas a $20^{\circ} \mathrm{C}(\mathrm{A}), 25^{\circ} \mathrm{C}(\mathrm{B})$ e $30^{\circ} \mathrm{C}(\mathrm{C})$, embebidas em $75 \mathrm{ml}$ de água deionizada, por diferentes períodos de embebição. 
to da temperatura e do período de embebição foram mais nítidos. Contudo, considerados em conjunto, os valores de $\mathrm{CE}$ aumentaram com a temperatura e com o período de embebição, independente da qualidade do lote de sementes (Figuras 1A, B e C).

Pode-se verificar que a diferenciação do lote III dos lotes I e II, deu-se em períodos diferentes, em cada uma das temperaturas estudadas (Tabela 2). Assim, a $30^{\circ} \mathrm{C}$ foi possível discriminar os lotes quanto à sua qualidade fisiológica, a partir de 12 horas. Isto só foi possível após 18 horas a $25^{\circ} \mathrm{C} \mathrm{e}$ após 24 horas à temperatura de $20^{\circ} \mathrm{C}$. Desta forma, os lotes II e I, podem ser considerados como de qualidade superior e o lote III como o de pior. Em todas as situações o lote II apresentou menores valores de CE, seguido pelo lote I e, por último, pelo lote III (Tabela 2).

Na temperatura de $20^{\circ} \mathrm{C}$, só se começa a notar diferença significativa entre os lotes a partir de 18 horas de embebição, quando o lote II diferiu do lote III, mas os lotes I e III não diferiram entre si. Somente a partir de 24 horas de embebição é que o lote III é, definitivamente, identificado como o de qualidade inferior (Tabela 2 e Figura $1 \mathrm{~A}$ ). A $25^{\circ} \mathrm{C}$, com 12 horas de embebição, o lote III diferiu significativamente do lote II, mas não diferiu do lote I. No entanto, a partir de 18 horas de embebição, nesta temperatura, a discriminação dos lotes já estava definida, como sendo os lotes I e II superiores ao lote III. Com 30 e 36 horas de embebição, a $25^{\circ} \mathrm{C}$, houve diferença significativa nos valores de condutividade elétrica entre os lotes estudados, sendo que neste caso, o lote II, foi superior ao lote I e esse superior ao III. Apenas nesta condição houve discriminação dos lotes em três classes de vigor (Tabela 2 e Figura 1B).

Para as sementes embebidas a $30^{\circ} \mathrm{C}$, já com seis horas, nota-se diferença do lote III para o lote II. Nos demais períodos de embebição, não é possível notar diferença significativa entre os lotes I e II, mas estes sempre diferiram significativamente do lote III. Nesta condição, praticamente não há diferença entre os lotes I e II (Tabela 2; Figura 1C). Vanzolini \& Nakagawa (1999) observaram para sementes de amendoim que, com três horas já foi possível a separação do lote de qualidade inferior, dentre os lotes avaliados. Rodo et al. (1998) mostraram que em sementes de tomate, a partir de quatro horas foi possível observar a diferença entre os lotes.

Analisando-se os coeficientes de correlação simples entre os valores de condutividade elétrica com as características avaliadas em laboratório e em viveiro (Tabela 3 ), verifica-se que, nas temperaturas de 20 e $25^{\circ} \mathrm{C}$, a partir de 12 horas de embebição, e na temperatura de $30^{\circ} \mathrm{C}$, já com seis horas de embebição, estes foram significativos a pelo menos $5 \%$ de probabilidade. Em termos absolutos, os maiores coeficientes de correlação, de uma maneira geral, foram verificados com 24 horas de embebição, independente da temperatura de embebição das sementes. Estes resultados evidenciam a alta correspondência entre os valores de condutividade elétrica na solução de embebição das sementes com a qualidade fisiológica dos lotes e sua alta associação com os resultados dos testes de germinação.

\section{CONCLUSÕES}

- O teste de condutividade elétrica é eficiente na diferenciação de lotes de sementes de Dalbergia nigra, apresentando alta correlação com a germinação, em condições de laboratório e viveiro;

- por questões de praticidade, facilidade operacional e rapidez na obtenção dos resultados, recomenda-se realizar o teste de condutividade elétrica a $25^{\circ} \mathrm{C}$, com 30 ou 36 horas de embebição, na avaliação da qualidade fisiológica de sementes de jacarandá-da-bahia.

\section{REFERÊNCIAS}

AOSA - ASSOCIATION OF OFFICIAL SEED ANALYSTS. Seed vigor testing handbook. East Lasing, 1983. 93p. (Contribution, 32).

BARBEDO, C.J \& CÍCERO, S.M. Utilização do teste de condutividade elétrica para previsão do potencial germinativo de sementes de ingá. Scientia Agricola, Piracicaba, v. 55, n.2, p.249-259, 1998.

BONNER, FT.; VOZZO, J.A.; ELAN, W.W. \& LAND-JR., S.B. Tree seed technology training course: student outline. New Orleans: U.S. Department of Agriculture, Forest Service, Southern Forest Experiment Station, 1994. 81p. (General Technical Report, SO-107).

BORGES, E.E.L.; CASTRO, J.L.D. \& BORGES, R.C.G. Avaliação fisiológica de sementes de cedro submetidas ao envelhecimento precoce. Revista Brasileira de Sementes, Brasília, v.12, n.1, p.56-62, 1990.

BORGES, E.E.L.; CASTRO, J.L.D. \& BORGES, R.C.G. Alterações fisiológicas em sementes de jacaré (Piptadenia communis) submetidas ao envelhecimento precoce. Revista Brasileira de Sementes, Brasília, v.14, n.1, p.9-12, 1992.

BRASIL. Ministério da Agricultura e Reforma Agrária. Regras para análise de sementes. Brasília: SNDA/DNDV/CLAV, 1992. $365 \mathrm{p}$.

DELOUCHE, J.C. \& BASKIN, C.C. Accelerated aging techniques for predicting the relative storability of seed lots. Seed Science and Tecnology, Zürich, v.1, n.2, p.427-457, 1973. 
DIAS, D.C.F.S. \& MARCOS-FILHO, J. Teste de condutividade elétrica para avaliação do vigor de sementes de soja. Scientia Agrícola, Piracicaba, v.53, n.1, p.31-42, 1996.

FERRAZ, I.D.K.; LIMA, V.N.S. \& COSTA, M.M. Testes de viabilidade em sementes de Carapa procera. In: SIMPÓSIO BRASILEIRO SOBRE TECNOLOGIA DE SEMENTES FLORESTAIS, 2, Atibaia, 1989. Anais. São Paulo: Instituto Florestal, 1991. p.39. (Série Documentos).

LEOPOLD, A.A. Temperature effects os soybean imbibition and leakage. Plant Physiology, Rockville, v.65, n.4, p.1096-1098, 1980.

LOEFFLER, T.M.; TEKRONY, D.M. \& EGLI, D.B. The bulk condutivity test as na indicator of soybean seed quality. Journal of Seed Technology, Springfield, v.12, n.1, p.37-53, 1988.

MAGUIRE, J.A. Speed of germination aid in selection and evaluation for seedling emergence and vigor. Crop Science, Madison, v.2, n.2, p.176-177, 1962.

MARCOS-FILHO, J.; CÍCERO, S.M. \& SILVA, W.R. Avaliação da qualidade das sementes. Piracicaba: FEALQ, 1987. 230p.

MURPHY, J.B. \& NOLAND, T.L. Temperature effects on seed imbibition and leakage mediated by viscosity and membranes.
Plant Physiology, Rockville, v.69, n.2, p.428-31, 1982.

RIBEIRO, D.M.V.A. Adequação do teste de condutividade elétrica de massa e individual para avaliação da qualidade fisiológica de sementes de milho. LAVRAS: UFLA, 1999. 105p. (Tese Doutorado).

RIZZINI, C.T. Árvores e madeiras úteis do Brasil: manual de dendrologia brasileira. São Paulo: Editora da Universidade de São Paulo, 1972. 294p.

RODO, A.B.; TILLMANN, M.A.A.; VILLELA, F.A. \& SAMPAIO, N.V. Teste de condutividade elétrica em sementes de tomate. Revista Brasileira Sementes, Brasília, v.20, n.1, p.29-38, 1998.

TAO, J.K. Factors causing variantions in the condutivity test for soybean seeds. Journal of Seed Technology, Springfield, v.3, n.1, p.10-18, 1978.

VANZOLINI, S. \& NAKAGAWA, J. Teste de condutividade elétrica em sementes de amendoim: efeitos de temperatura e de período de embebição. Revista Brasileira de Sementes, Brasília, v.21, n.1, p.41-45, 1999.

VIEIRA, R.D. Teste de condutividade elétrica. In: VIEIRA, R.D. \& CARVALHO, N.M. (ed.). Testes de vigor em sementes. Jaboticabal: FUNEP, 1994. p.103-132. 